BMC

Immunology

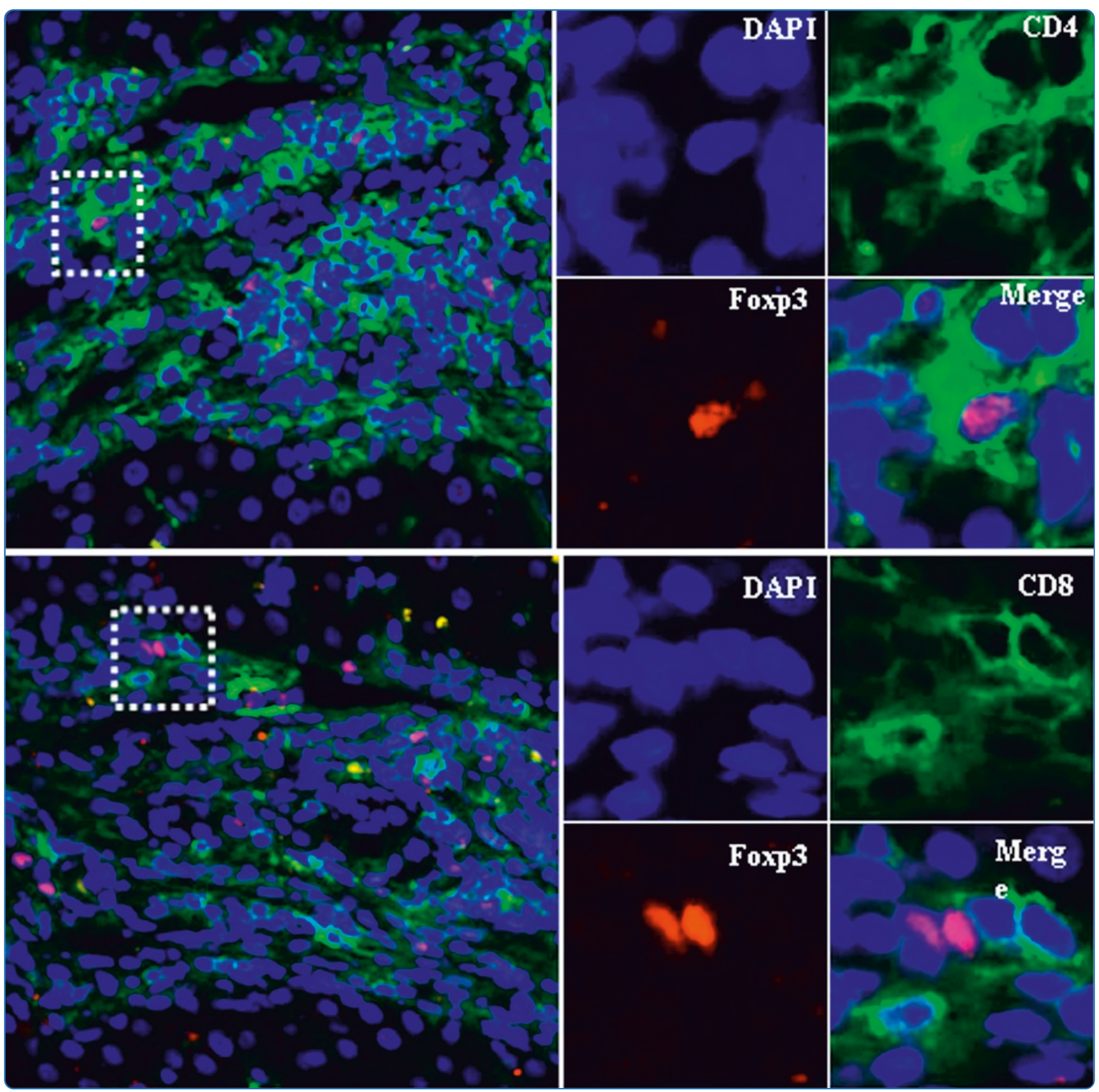

Activated IL-23/IL-17 pathway closely correlates with increased Foxp3 expression in livers of chronic hepatitis $B$ patients

Wang et al.

C BioMed Central

Wang et al. BMC Immunology 2011, 12:25

http://www.biomedcentral.com/1471-2172/12/25 (14 April 2011) 


\title{
Activated IL-23/L-17 pathway closely correlates with increased Foxp3 expression in livers of chronic hepatitis B patients
}

Qinghong Wang ${ }^{1,2+}$, Yanhua Zheng ${ }^{2+}$, Zemin Huang ${ }^{2}$, Yi Tian², Jijun Zhou ${ }^{3}$, Qing Mao ${ }^{3}$, Yuzhang $\mathrm{Wu}^{2^{*}}$ and Bing $\mathrm{Ni}^{2^{*}}$

\begin{abstract}
Background: Foxp3 protein plays a critical role in mediating the inflammatory response and can inhibit the proinflammatory IL-23/IL-17 pathway. However, the molecular interplay of Foxp3 and the IL-23/IL-17 pathway in patients with chronic hepatitis B (CHB) remains unclear. To this end, we analyzed the expression patterns of Foxp3and IL-23/L-17 pathway-related proinflammatory cytokines in 39 patients with acute-on-chronic liver failure, 71 patients with $\mathrm{CHB}$ and 32 healthy controls.

Results: Foxp3 expression was found to be elevated in and mainly expressed by the CD4 ${ }^{+} \mathrm{T}$ cell sub-population of peripheral blood mononuclear cells and liver tissues of patients with hepatitis B. The intrahepatic expression of Foxp3 strongly correlated with the copies of HBV DNA and the concentration of surface antigen, HBsAg. IL-23/LL-17 pathway-related proinflammatory cytokines were also found to be significantly increased in patients' liver tissues, as compared to healthy controls. Moreover, Foxp3 expression was strikingly correlated with the production of these cytokines in liver tissues of CHB patients.
\end{abstract}

Conclusions: The closely-correlated increase of Foxp3 and IL-23/IL-17 pathway activity in HBV-infected livers suggests that the proinflammatory IL-23/L-17 pathway had not been effectively suppressed by the host immune machinery, such as Treg (Foxp3) cells. Constitutive activation of the IL-23/17 pathway, thus, may support the chronic hepatitis B state.

Keywords: Treg Foxp3, Th17, IL-23, IL-17, Hepatitis B

\section{Background}

Hepatitis B virus (HBV) is a noncytopathic, hepatotropic DNA virus that is capable of inducing acute and chronic necroinflammatory liver injury [1]. Outcome of patients infected with HBV is closely associated with the extent of host immune response [2]. Moderate immune responses will mediate the clearance of HBV infection, while excessive responses will induce liver injury and low level responses will allow HBV residence. Unfortunately, patients with chronic hepatitis B (CHB) often exhibit impaired HBV-specific $\mathrm{T}$ cell responses [3]. The exact mechanisms of the immune system that fail in

\footnotetext{
* Correspondence: wuyuzhang@yahoo.com; nibingxi@yahoo.com

+ Contributed equally

${ }^{2}$ Institute of Immunology, PLA, Third Military Medical University, Chongqing 400038, PR China

Full list of author information is available at the end of the article
}

$\mathrm{CHB}$ infections remain unclear and, thus, remain a hindrance to the development of effective therapies.

Many mechanisms have been hypothesized to explain the inadequate immune responses that facilitate chronic HBV infection. The most recent has focused on the dysfunction of regulatory $\mathrm{T}$ (Treg) cells. Treg cells are characterized by their cell-specific expression of Forkhead box P3 (Foxp3) [4], a transcription factor that contributes to autoimmune functions. Studies have demonstrated that Foxp $3^{+}$Treg cells can inhibit activation, proliferation and effector functions of several kinds of other immune cells, including $\mathrm{CD}^{+}$and $\mathrm{CD}^{+}{ }^{+} \mathrm{T}$ cells, natural killer (NK) and NKT cells, B cells and dendritic cells (DC). As such, Foxp $3^{+}$Treg cells are widely considered to be the principal mediator of dominant selftolerance and immune homeostasis and to contribute to
C Biomed Central

() 2011 Wang et al; licensee BioMed Central Ltd. This is an Open Access article distributed under the terms of the Creative Commons Attribution License (http://creativecommons.org/licenses/by/2.0), which permits unrestricted use, distribution, and reproduction in any medium, provided the original work is properly cited. 
prevention of autoimmune disease, immunopathology and allergy [5]. In HBV patients, Foxp $3^{+}$Treg cells have been associated with the incidence and extent of liver damage [6-10].

Chronic inflammation of the liver, known as hepatitis, is most commonly caused by infection with HBV. Many other inflammation-related diseases, such as multiple sclerosis, psoriasis, rheumatoid arthritis, inflammatory bowel disease, and asthma $[5,11,12]$, have been characterized as having significant dysfunctions in the interleukin (IL)-23/IL-17 signaling pathway. Interestingly, IL-17 has been associated with the pathogenesis of chronic hepatitis B in humans [13,14]; however, the relationship between Foxp $3^{+}$Tregs and the IL-23/IL-17 pathway (via Th17 cells) has not yet been investigated in HBV infected individuals.

This study was designed to elucidate the Foxp3mediated activity of the IL-23/IL-17 signaling pathway in $\mathrm{HBV}$-infected patients. We found that both Foxp3 and IL-23/IL-17 pathway-related cytokines were sharply increased in patients with $\mathrm{CHB}$, as compared to healthy controls. We also determined that Foxp3 gene expression was positively associated with the presence of IL23/IL-17 pathway cytokines at sites of inflammation. These findings suggest that both Foxp3 and the IL-23/ IL-17 pathway are involved in inflammatory response to hepatitis $\mathrm{B}$ infection, and may interact with one another in $\mathrm{CHB}$ patients.

\section{Methods}

\section{Patients and samples}

One hundred and ten $\mathrm{HBV}$-infected patients including thirty-nine acute-on-chronic liver failure (ACLF) and seventy-one chronic hepatitis $\mathrm{B}$ patients $(\mathrm{CHB})$ were recruited for the study and enrolled when written, informed consent was obtained. Each patient was hospitalized and clinically followed upon release in the Department of Infectious Diseases, Southwest Hospital, Third Military Medical University. The study period lasted from December 2007 to January 2010. All individuals were confirmed as $\mathrm{HBV}$ positive, and negative for $\mathrm{C}$ and D types (HCV, HDV) and human immunodeficiency virus. Clinical records and self-reporting indicated that no anti-HBV agents or steroids were administered six months before study sampling. Twenty-four healthy blood donors (healthy controls, $\mathrm{HC}$ ) and eight healthy liver tissue samples from liver transplantation patients were also selected. The study was approved by the ethics committee of the Third Military Medical University, Chongqing, China. Informed consent was obtained from all patients. The clinical characteristics of our patient cohort and healthy controls are shown in Table 1.

\section{Flow cytometry (FCM) analysis}

The following antibodies were used: AF750-conjugated anti-CD3 (eBioscience, San Diego, CA, USA), PerCPCy5.5conjugated anti-CD4, and APC-conjugated antiFoxp3. Peripheral blood mononuclear cells (PBMC) were obtained by Ficoll gradient. Cells were then stained to detect relevant surface markers, fixed, permeabilized with Cytofix/Cytoperm solution (BD Biosciences), and stained with anti- Foxp3. Detection was carried out on a FACSAria cell sorter (BD Biosciences), and data were analyzed by FlowJo v. 6.1 (TreeStar, Inc., Ashland, OR, USA).

\section{Total RNA isolation and quantitative PCR}

PBMC and liver tissues were dissolved in TRIzol (Invitrogen, Carlsbad, CA, USA) for total RNA extraction. RT-PCR was carried out on the RNA product by using the PrimeScript ${ }^{\mathrm{TM}} \mathrm{RT}$ reagents kit (TaKaRa, Shiga, Japan), following the manufacturer's directions. Quantitative real-time (q)PCR was performed using the SYBR ${ }^{\circledR}$ Premix Ex Taq ${ }^{\mathrm{TM}}$ (TaKaRa). Gene-specific primers for human IL-17, IL-23, Foxp3, TNF- $\alpha$ and IL- 8 were designed as shown in Table 2. Fluorescence signals were measured after 40 PCR cycles, and all samples were normalized to GAPDH housekeeping gene levels. All samples were run in duplicate.

\section{Immunohistochemistry analysis}

Liver tissues were embedded in paraffin using the standard protocol. Immunohistochemistry for human Foxp3 was performed as previously described, with minor modifications [9]. Briefly, masked antigens were uncovered by microwaving for $20 \mathrm{~min}$ in citrate buffer, $\mathrm{pH}$ 6.0. After cooling at room temperature, non-specific binding was blocked by exposure to $5 \%$ bovine serum albumin (BSA) in phosphate-buffered saline (PBS) for $30 \mathrm{~min}$. Incubation with primary antibodies for Foxp3 (Abcam, Cambridge, MA, USA) was carried out for $48 \mathrm{~h}$ at $4^{\circ} \mathrm{C}$ in a humidified chamber before the slides were incubated with secondary, biotin-conjugated antibody, followed by sequential incubation with horseradish peroxidase-streptavidin and the peroxidase substrate 3'-diaminobenzidine. Samples were then counterstained with hematoxylin.

For the double staining of anti- Foxp3 plus anti-CD4 and anti- Foxp3 plus anti-CD8, the first antibody (diluted 1:200) was applied for $48 \mathrm{~h}$ at $4^{\circ} \mathrm{C}$ in a humidified chamber. The second antibody, anti-human CD4 and CD8 (diluted 1:100 in PBS containing 5\% BSA; eBioscience), was then applied for overnight at $4{ }^{\circ} \mathrm{C}$. CY3-labeled anti-goat IgG (diluted 1:500 in PBS) and Dylight488-labeled anti-mouse IgG (diluted 1:200) (Zhongshan Goldenbridge Biotechnology, Beijing, China) were applied for $60 \mathrm{~min}$ at $37^{\circ} \mathrm{C}$. Nuclear counterstaining was performed by incubating stained samples 
Table 1 Clinical characteristics of the study's subjects

\begin{tabular}{lllllllll}
\hline Subjects & Cases & Sex (F/M) & Age in years (mean, range) & ALT in U/L (mean, range) & HBsAg $^{+}$ & HBeAg $^{+}$ & HBcAb $^{+}$ & HBV DNA $^{+}$ \\
\hline $\mathrm{HC}$ & 32 & $4 / 14$ & $27(17-42)$ & $<40$ & 0 & 0 & 0 & 0 \\
$\mathrm{CHB}$ & 71 & $8 / 63$ & $32(18-42)$ & $136(53-326)$ & 71 & 71 & 71 & 71 \\
$\mathrm{ACLF}$ & 39 & $3 / 36$ & $28(20-39)$ & $206.34(92-1675)$ & 39 & $9 / 39$ & 39 & 39 \\
\hline
\end{tabular}

with diaminidophenylindol (DAPI, 1:100 in PBS; D1306, Invitrogen) for $5 \mathrm{~min}$. Normal mouse or goat IgG was used as a negative control. Images were obtained by the digital confocal laser scanning system MRC-600 (BioRad, Hercules, CA, USA).

\section{Western blot}

Total protein of liver tissue was extracted using T-PER ${ }^{\circledR}$ Tissue Protein Extraction Reagent (Pierce, Rockford, IL, USA) and quantified with BCA ${ }^{\mathrm{TM}}$ Protein Assay (Pierce). The proteins were separated on a $16 \%$ SDS-PAGE and transferred onto polyvinylidene fluoride (PVDF) membranes for immunoblotting. The membranes were incubated with goat anti-human IL-17 (R\&D Systems, Wiesbaden, Germany), mouse anti-human IL-23p19 (BioLegend, San Diego, CA, USA) and mouse anti-human Foxp3 (eBioscience, San Diego, CA, USA) for $1 \mathrm{~h}$ at room temperature, respectively. After incubation with peroxidase-conjugated rabbit anti-goat IgG, or rat anti-mouse IgG for $1 \mathrm{~h}$ at room temperature, specific protein bands on the membranes were visualized by the enhanced chemiluminescence method (Amersham, Piscataway, NJ, USA), according to the manufacturer's instructions.

\section{Virological assessment}

The virological assay was performed as previously described [15].

\section{Statistical analysis}

Comparisons between various groups were performed using the Mann-Whitney $U$ test. Results are expressed as the mean \pm standard deviation (SD), unless otherwise

Table 2 Primer design for detection of target genes

\begin{tabular}{|c|c|c|}
\hline Genes & Forward primer & Reverse primer \\
\hline Foxp3 & $\begin{array}{l}\text { 5'-AAGGAAAGGAGGATGGACG- } \\
3^{\prime}\end{array}$ & $\begin{array}{l}5^{\prime} \text {-CAGGCAAGACAGTGGAAACC- } \\
3^{\prime}\end{array}$ \\
\hline |L-23 & 5'-GCTTCAAAATCCTTCGCAG-3' & $\begin{array}{l}\text { 5'-TATCTGAGTGCCATCCTTGAG- } \\
3^{\prime}\end{array}$ \\
\hline IL-17 & 5'-TCAACCCGATTGTCCACCAT-3' & $\begin{array}{l}\text { 5'- } \\
\text { GAGTTTAGTCCGAAATGAGGCTG- } \\
3^{\prime}\end{array}$ \\
\hline |L-8 & $\begin{array}{l}5^{\prime}- \\
\prod_{3^{\prime}}\end{array}$ & $\begin{array}{l}\text { 5'- } \\
\text { GGGTGGAAAGGTITGGAGTATG- } \\
3^{\prime}\end{array}$ \\
\hline TNF- $\alpha$ & $\begin{array}{l}5^{\prime}- \\
\text { ATGAGCACTGAAAGCATGATCC- } \\
3^{\prime}\end{array}$ & $\begin{array}{l}\text { 5'- } \\
\text { GAGGGCTGATTAGAGAGAGGTC- } \\
3^{\prime}\end{array}$ \\
\hline
\end{tabular}

noted. Correlations between variables were evaluated using the Spearman's rank correlation. For all tests, 2sided $P<0.05$ was considered significant.

\section{Results}

Foxp3 expression is significantly high in peripheral blood of CHB patients

Tregs with transcription factor Foxp3 play an pivotal role in controlling immune response mediated inflammation [16]. Several reports have shown evidence that Treg cells are involved in hepatitis B pathogenesis [6-10]. To further explore the role of Foxp3 in patients with hepatitis $\mathrm{B}$, we collected the peripheral blood from $34 \mathrm{CHB}$ patients and 30 ACLF patients, and then evaluated the expression of Foxp3 as detected by qPCR and FCM assays. As shown in Figure 1A, the expression of Foxp3 mRNA was found to be significantly increased in PBMC of CHB and ACLF patients, as compared with healthy controls. FCM assays indicated that the Foxp3 ${ }^{+}$ $\mathrm{T}$ cell portion of $\mathrm{CD} 4^{+} \mathrm{T}$ cells were markedly up-regulated in HBV-infected patients; the ACLF patients had the most Foxp3 ${ }^{+} \mathrm{T}$ cells (Figure $1 \mathrm{~B}$ and $1 \mathrm{C}$ ).

\section{Foxp3 is significantly augmented in liver tissue of} patients infected with HBV

To further value the role of Foxp3 in patients with hepatitis B, we detected the expression level of Foxp3 in liver tissue from patients infected by HBV by using qPCR and immunohistochemistry techniques. Concordant with the data from $\mathrm{Xu}$ et al. [9] and Janssen's group [8], Foxp3 was found to be mainly localized to cells near the hepatic portal tract, and Foxp3 expression was significantly higher in HBV patients than in healthy controls (Figure 2A and 2B). We further investigated the distribution patterns of Foxp3 expression in HBVinfected liver tissue by immunofluorescent confocal microscopy. Results revealed that Foxp3 in HBVinfected liver tissues was predominantly present in CD4 ${ }^{+} \mathrm{T}$ cells, and not in $\mathrm{CD}^{+} \mathrm{T}$ cells (Figure $2 \mathrm{C}$ and $2 \mathrm{D}$ ).

\section{Increased Foxp3 expression is positively correlated with} HBV persistence in host liver

In order to evaluate the relationship between Foxp3 expression and clinical symptom of patients with $\mathrm{CHB}$, we analyzed the Foxp3 expression in liver tissue and plasma HBV DNA copies, hepatitis B surface antigen (HBsAg) concentration, and serum alanine 
A

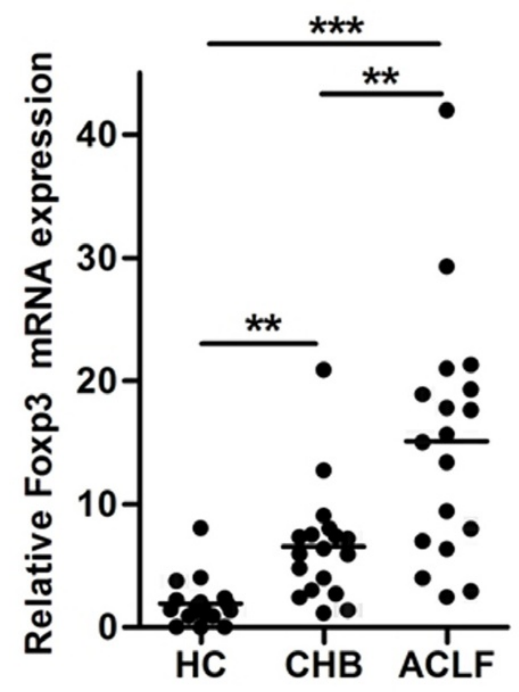

C

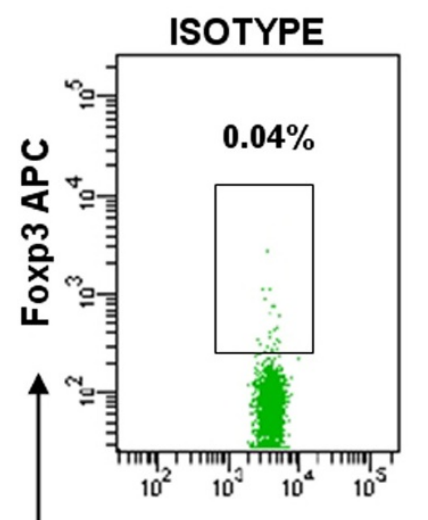

$\mathrm{C}$
B

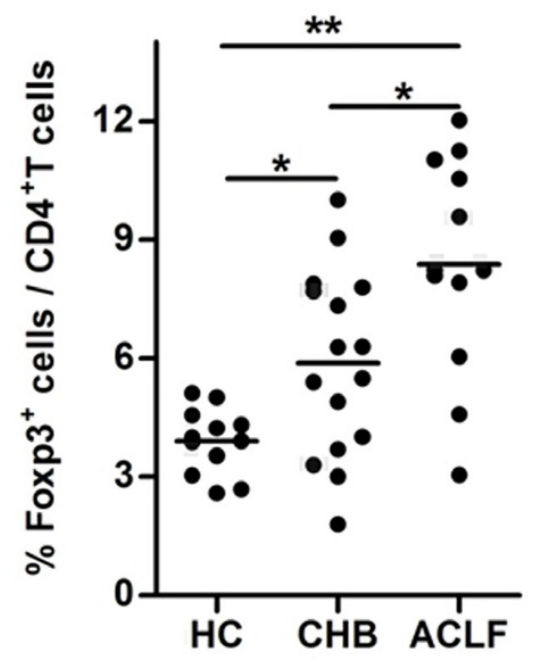

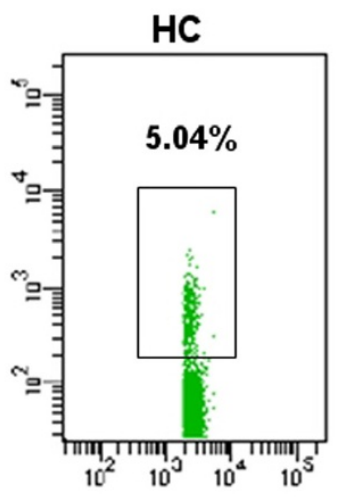

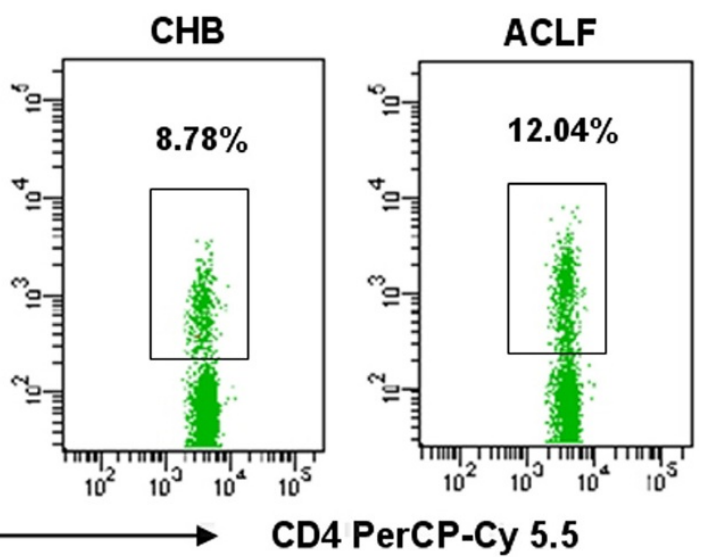

Figure 1 Foxp3 expression is significantly higher in peripheral blood of patients with $\mathrm{CHB}$. PBMC from healthy controls and patients with CHB or ACLF were used to detect the expression levels of Foxp3 by qPCR (A) and flow cytometry (B and $\mathbf{C})$. (A) Relative mRNA expression of Foxp3 in PBMC. (B) Pooled data indicating the percentages of Foxp3 ${ }^{+}$cells in total CD4 $^{+}$T cells. (C) Representative dotplots of Foxp3 ${ }^{+}$cells in $\mathrm{CD}^{+} \mathrm{T}$ cells. The values in the quadrants indicate the percentage of each $\mathrm{CD}^{+} \mathrm{T}$ cell subset. Error bars indicate SD; ${ }^{*}, P<0.05 ;{ }^{* *}, P<0.01 ;{ }^{* *}$, $P<0.001$.

aminotransferase (ALT) level in $38 \mathrm{CHB}$ patients. There was significant association between Foxp3 expression and HBV DNA copies or HBsAg concentration, but not ALT (Figure 3). These results suggested that Foxp3 was involved in the persistent presence of $\mathrm{HBV}$ in $\mathrm{CHB}$ patients, but not directly involved in liver injury.

\section{Expression of IL-23/IL-17 pathway proinflammatory} cytokines was significantly high in HBV-infected liver tissues

Inflammatory responses are significant features of hepatitis B pathogenesis. It has been reported that the IL-23/ IL-17 pathway plays a critical role in inflammatory diseases $[17,18]$. Moreover, Foxp3 is closely related to the IL-23/IL-17 signaling pathway [19]. In order to further elucidate the role of Foxp3 in patients with $\mathrm{CHB}$, we detected the expression of IL-23/IL-17 pathway-related cytokines in $\mathrm{CHB}$ liver samples. As shown in Figure 4A, the mRNA expression of IL-23, IL-17, TNF- $\alpha$, and IL- 8 was significantly higher in these patients liver tissues than in healthy controls. We then investigated whether the protein expression of the key genes, Foxp3, IL-23 and IL-17 genes, was also enhanced in $\mathrm{CHB}$ liver tissues by Western-blot assay. Results showed that the protein expression of these three genes in liver tissue of $\mathrm{CHB}$ patients was significantly elevated 
A

B
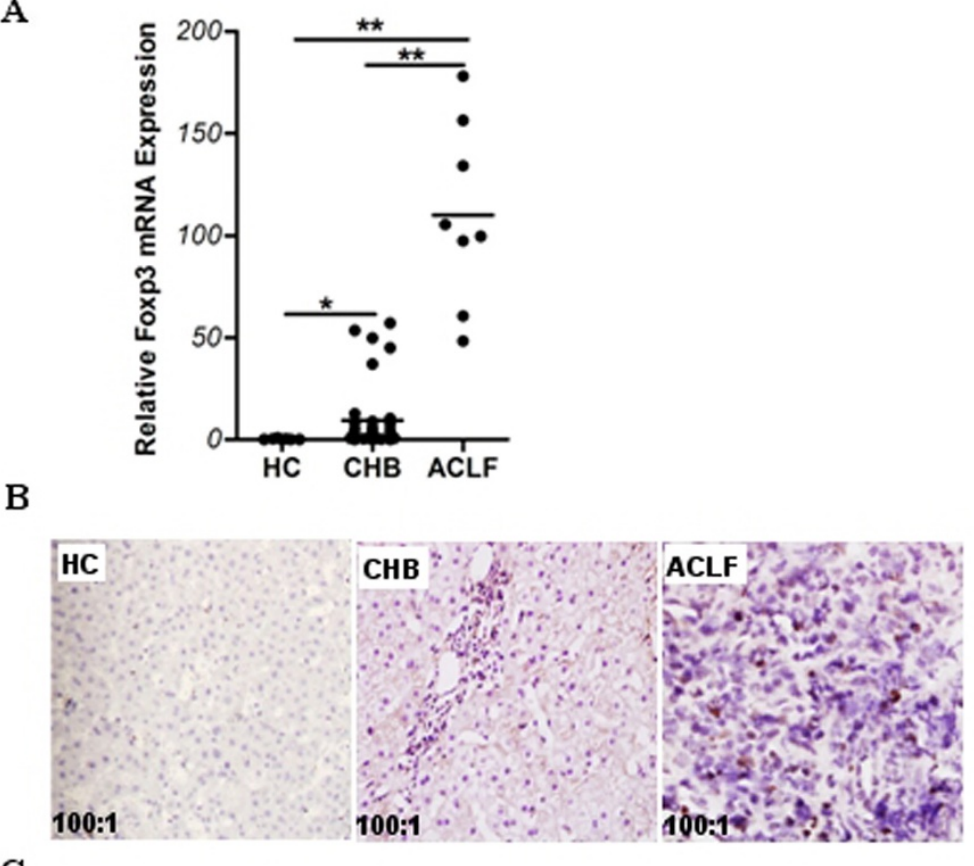

$\mathrm{C}$

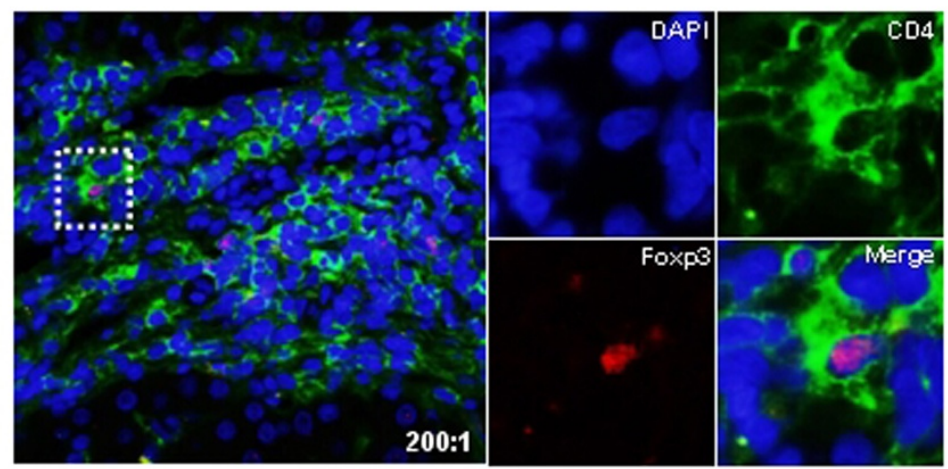

D

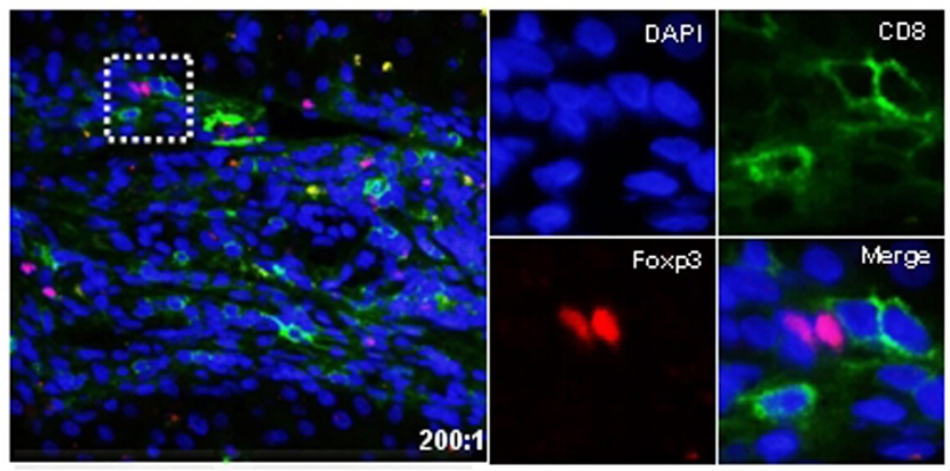

Figure 2 Foxp3 is significantly augmented in liver tissue of patients infected with HBV. Liver biopsy samples from healthy controls and patients with CHB or ACLF were used for the detection of Foxp3 mRNA by qPCR (A) and visualization of Foxp3 by immunohistochemistry (B) and laser scanning confocal microscopy $(\mathbf{C}, \mathbf{D})$. (A) Relative mRNA expression of Foxp3 in liver tissues. Error bars indicate SD; ${ }^{*}, P<0.05 ; *^{* *}, P<$ 0.01. (B) In situ expression of Foxp3 in liver tissues. The Foxp3 expressing cells are stained brown. Representative results are shown from three independent experiments (100 × magnification). (C, D) Co-localization of Foxp3 with CD4 or CD8 in liver tissues from CHB patients. Anti- Foxp3 (red); anti- CD4 (green); anti- CD8 (green); and DAPI (blue). Representative results are shown from three independent experiments (200 $\times$ magnification). The right panels represent the enlarged portion of the indicated (white hatched box) area in the left panels. 

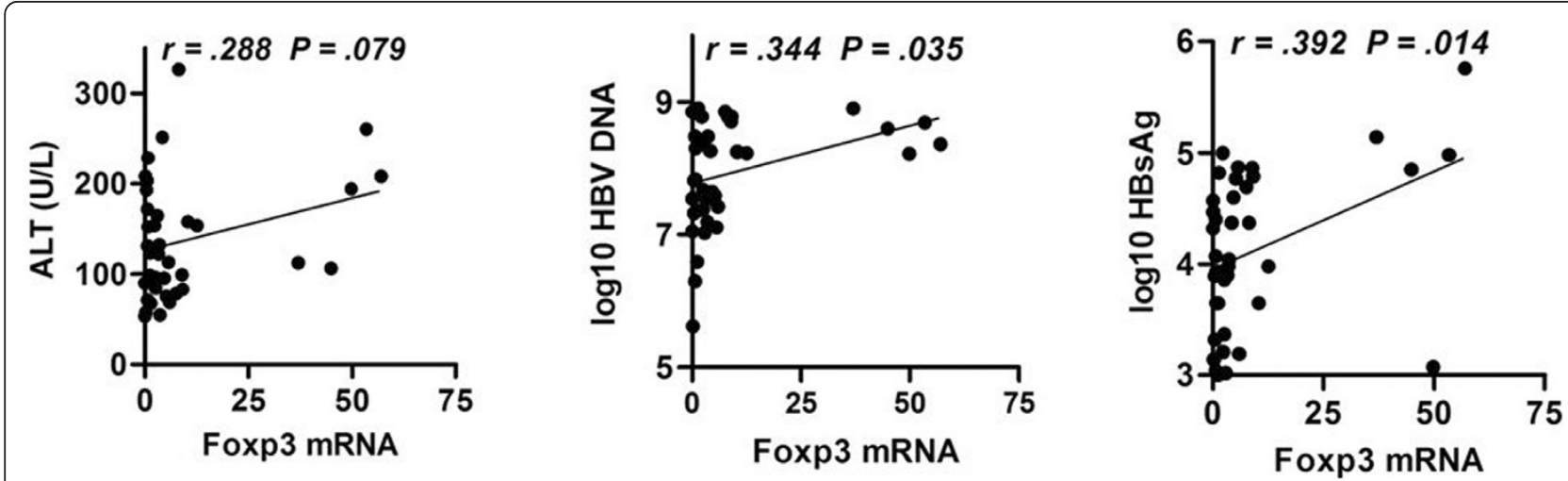

Figure 3 Increased Foxp3 expressions is positively correlated with HBV persistence in host liver. Liver biopsy samples from 38 CHB patients were used for the detection of Foxp3 mRNA by qPCR. Sera and plasma samples from CHB patients were measured for ALT level, log 10 $\mathrm{HBsAg}(\mathrm{IU} / \mathrm{ml})$, or log $10 \mathrm{HBV}$ loads (copies/ml). The relationships between Foxp3 and clinical symptoms of these patients were analyzed. $P<0.05$ was considered significant.

in comparison with that of $\mathrm{HC}$ (Figure 4B), suggesting Treg cells and Th17 cells might play important roles simultaneously in $\mathrm{CHB}$ pathogenesis.

Foxp3 expression is positively correlated with presence of IL-23/IL-17 pathway-related cytokines in liver tissue from CHB patients

Foxp3 is a potent mediator of dominant self-tolerance and immune homeostasis. Nistala et al. [20] demonstrated an inverse relationship between $\mathrm{IL}-17^{+} \mathrm{T}$ cells and Foxp $3^{+}$Treg cells in joint tissues of children suffering from juvenile arthritis. The fact that Foxp3 and IL23/IL-17 pathway cytokines were both significantly increased in patients with $\mathrm{CHB}$ led us to examine the relationship between these molecules in liver tissues infected with HBV. We found that Foxp3 was significantly correlated with the presence of IL-23 and IL-17 at sites of inflammation (Figure 5).

\section{Discussion}

Immune-mediated liver injury is the key feature of hepatitis B pathogenesis. Recently, much attention has been paid to the importance of Treg cells in chronic HBV infection [21]. In the study described herein, we investigated the expression levels of Foxp3 (the cell-specific transcription factor of Treg cells) and IL-23/IL-17 pathway-related cytokines in $\mathrm{HBV}$-infected liver tissue. We found that Foxp3 and IL-23/IL-17 pathway-related cytokines were significantly higher at sites of inflammation. Moreover, the expression of Foxp3 was closely correlated with the presence of IL-23/IL-17 pathway-related cytokines.

The inflammatory response is necessary to clearance of pathogenic agents, but a fine balance must be maintained so that chronic inflammation does not damage healthy tissues. Treg cells that express Foxp3 play a key role in regulating this delicate equilibrium [22]. Several studies of HBV infection have found that Treg cells are functionally involved in the hepatic immunological responses [6-10]. Likewise, we also observed Foxp3 expression in $\mathrm{CD}_{4}^{+} \mathrm{T}$ cells, and not in $\mathrm{CD}^{+} \mathrm{T}$ cells. Moreover, the expression of Foxp3 was significantly increased and in liver tissue of $\mathrm{CHB}$ patients. Moreover the mRNA level of Foxp3 at sites of hepatic inflammation was closely correlated with levels of HBV DNA copies and HBsAg. These results indicated that Foxp3 expression was likely to support established residence of HBV.

Recently, clinical investigations have shown that the IL-23/IL-17 signaling pathway contributes to the inflammatory reaction of Crohn's disease, psoriasis and systemic lupus erythematosus $[18,23,24]$. IL-17 is known as the immune-modulatory factor of Th17 cells, while IL23 functions to elicit the differentiation and mediate the function of Th17 cells [25]. Several groups have reported that the IL-17 pathway was involved in human liver disease [13,14,26,27]. Our results evidenced that the activity of the IL-23/IL-17 pathway was significantly elevated in liver tissues of patients infected by hepatitis $B$ virus, as compared to that in healthy controls. These results indicated that the IL-23/IL-17 pathway, rather than IL-17 alone, is involved in the pathological process of hepatitis B infection.

Th17 cells and Treg cells both arise from the naive $\mathrm{CD}_{4}^{+} \mathrm{T}$ cell population and share reciprocal development pathways. But, they have opposite immunomodulatory effects, and the balance between them controls inflammation and autoimmune diseases [28]. Many studies have identified an imbalance in Th17 cells and Treg cells that occurs in conjunction with disease [6,29-31]. In the present study, we found that expression of Foxp3 and IL-23/IL-17 pathway-related cytokines 


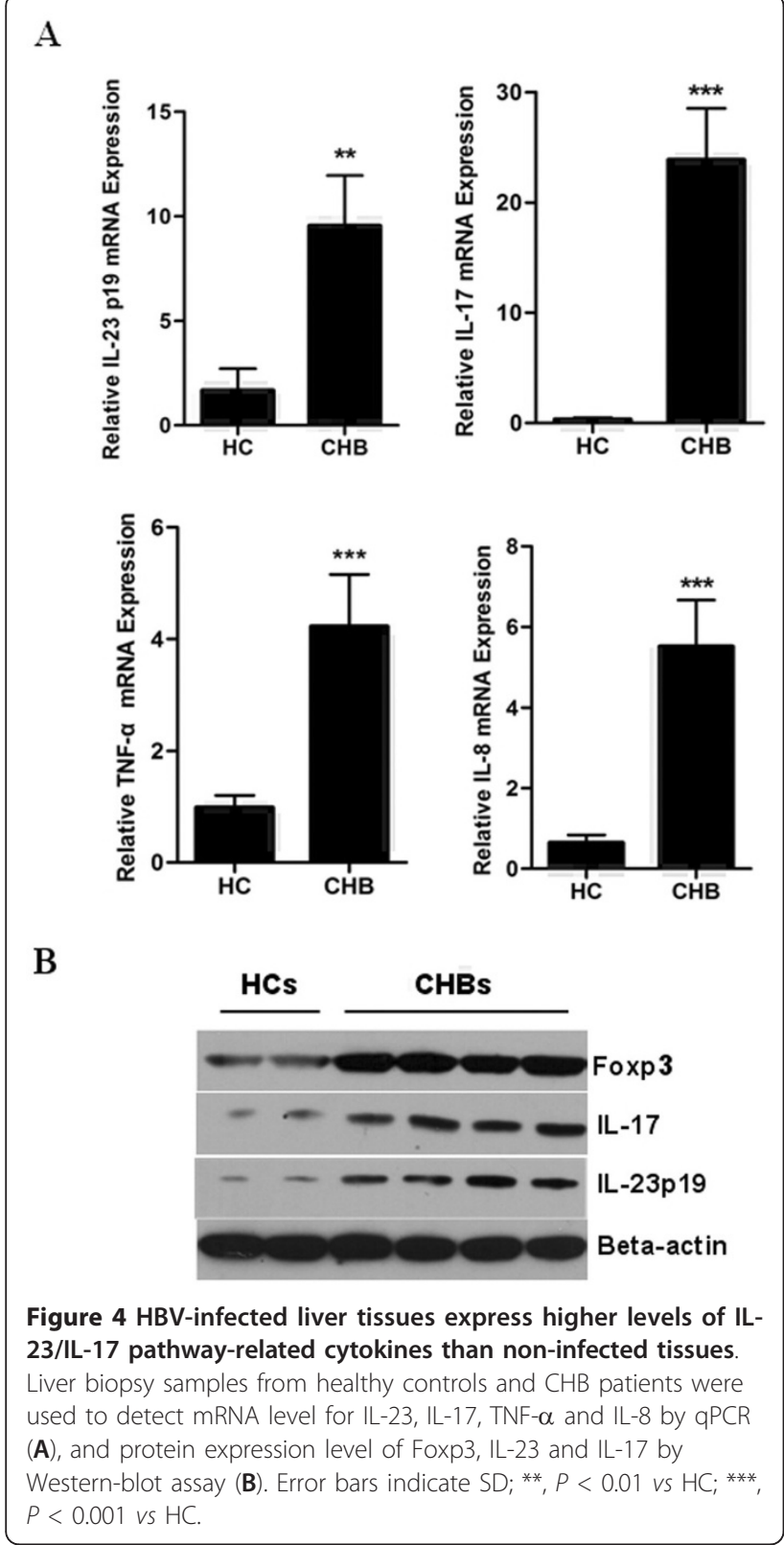

were increased in inflamed hepatic tissues in $\mathrm{CHB}$ patients. We also found that Foxp3 expression was significantly correlated with levels of IL-23/IL-17 pathwayrelated cytokines in the livers of these $\mathrm{CHB}$ patients (Figure 5). Several studies have demonstrated that the development of Th17 cells and Treg cells may be interrelated, as they are both dependent on TGF- $\beta$ [32]. Yet, they appear to be reciprocally influenced by various cytokines, such as IL-6, IL-1, as well as IL-2 and the vitamin A metabolite all-trans-retinoic acid [33-35]. TGF- $\beta$ is central to the development and function of Th17 and Treg cells. On one hand, TGF- $\beta$ induces the expression of FoxP3 [36]; on the other hand, TGF- $\beta$ has
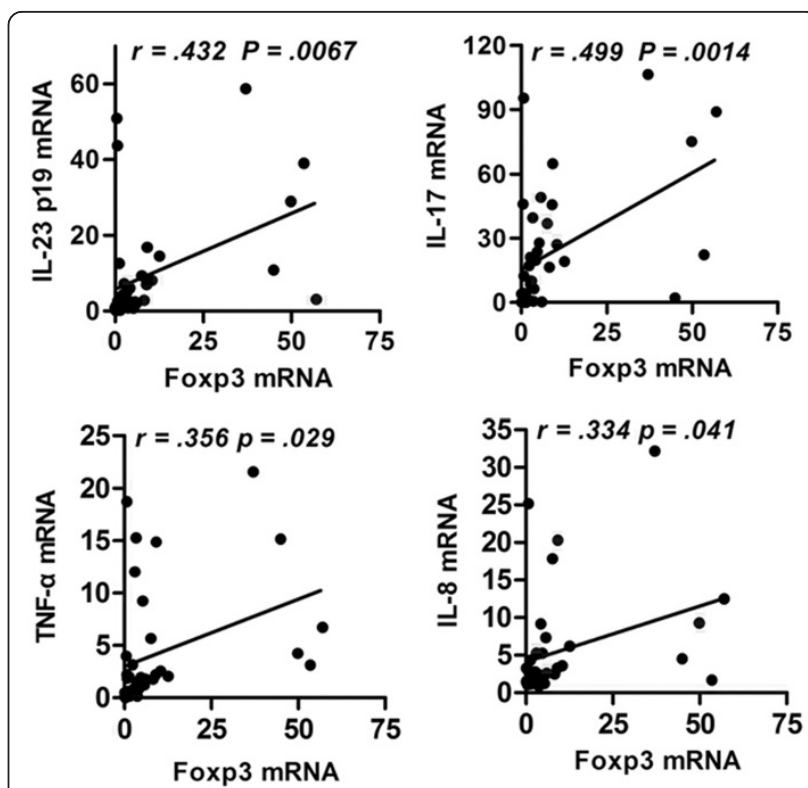

Figure 5 Foxp3 expression is positively correlated with IL-23/ IL-17 pathway in host liver. Liver biopsy samples from $38 \mathrm{CHB}$ patients were used to detect mRNA for Foxp3, IL-23, IL-17, TNF- $\alpha$ and IL- 8 by qPCR, and then the relationship between Foxp3 and IL23, IL-17, TNF- $\alpha$ or IL-8 was analyzed. $P<0.05$ was considered significant.

been shown to be absolutely required for Th17 differentiation in a serum-free system using cord blood-derived $\mathrm{CD} 4^{+} \mathrm{T}$ cells [37]. A recent study also showed that Tregs themselves may differentiate into IL-17-producing cells, particularly when exposed to exogenous IL-1 $\beta$, IL23 or IL-21 [38,39]. In psoriasis patients, Zhang et al. found that Th17 cells were positively correlated with the presence of Treg cells, both in the circulation and in skin tissue lesions [40]. Based on these data, we propose that Tregs may act to promote the pro-inflammatory cytokines, such as IL-17 and IL-23, at certain time points during the course of HBV infection. Considering that the inflammatory response is crucial for clearance of pathogenic microorganisms, it is reasonable that the occurrence of pro-inflammatory immune cells, such as Th17, will be accompanied by inhibitory Tregs cells. In this way, the significant correlation between Treg cells and Th17 cells in the liver of CHB patients is fitting.

\section{Conclusions}

We have demonstrated that Foxp3 and IL-23/IL-17 pathway-related cytokines were both highly expressed in inflamed liver tissues infected by hepatitis B virus. Moreover, the expression of Foxp3 was significantly correlated with that of IL-23/IL-17 pathway-related cytokine genes in the infected liver. These findings support the hypothesis that proinflammatory Th17 (IL-23/IL-17) cells in HBVinfected liver is accompanied by host inflammation- 
inhibitory machinery, such as Treg (Foxp3) cells, in order to maintain balance between promotion and inhibition of the immune response. Our results also suggested that the activity of the proinflammatory IL-23/IL-17 signaling pathway is not been efficiently controlled by the host inhibitory machinery, in this case the Treg (Foxp3) cells; the constitutive activation of the IL-23/IL-17 signaling pathway may partially explain the HBV persistence that occurs in the chronic hepatitis B state. Future studies will address the precise in vivo mechanism of the reciprocal regulation between Foxp3 and the IL-23/IL-17 pathway, and will contribute to development of effective therapies to clear HBV from CHB patients.

\section{List of Abbreviations Used}

HBV: hepatitis B virus; CHB: chronic hepatitis B; Treg: regulatory T cell; Foxp3: forkhead box P3; NK: natural killer cells; NKT: natural killer T cells; DC: dendritic cells; IL: interleukin; Th17: interleukin-17-producing CD4 ${ }^{+} \mathrm{T}$ cells; HCV: hepatitis C virus; HDV: hepatitis D virus; HC: healthy controls; FCM: flow cytometry; PBMC: peripheral blood mononuclear cells; BSA: bovine serum albumin; PBS: phosphate buffered saline; DAPI: diaminidophenylindol; ACLF: acute-on-chronic liver failure; SD: standard deviation; HBsAg: hepatitis B surface antigen; ALT: alanine aminotransferase; $\mathrm{HBCAg}$ : hepatitis B core Ag; HBeAg: hepatitis B e Ag.

\section{Acknowledgements and Funding}

This work was supported by the Major State Basic Research Development Program of China (973 Program) (Nos. 2007CB512401 and 2007CB512805), the General Program of National Natural Science Foundation of China (31070798) and the Chongqing Science and Technology Committee (2008BB5033).

\section{Author details}

${ }^{1}$ Ministry of Education Key Laboratory of Child Development and Disorders, Pediatric Research Institute, Children's Hospital of Chongqing Medical University, Chongqing 400014, PR China. ${ }^{2}$ Institute of Immunology, PLA, Third Military Medical University, Chongqing 400038, PR China. ${ }^{3}$ Department of Infectious Diseases, Southwestern Hospital, Third Military Medical University, Chongqing 400038, PR China.

\section{Authors' contributions}

QW carried out the FCM and quantitative PCR assays. YZ carried out the immunoassays and virological assessmen. ZH performed the statistical analysis. YT participated in the FCM analysis. JZ contributed to the preparation of blood and liver tissue samples from healthy and HBV-infected volunteers. YW and BN conceived of the study, and participated in its design and coordination and drafted the manuscript equally. All authors read and approved the final manuscript.

\section{Declaration}

There are no potential conflicts (financial, professional, or personal) that exist for any of the authors in regards to this manuscript.

Received: 5 November 2010 Accepted: 14 April 2011 Published: 14 April 2011

\section{References}

1. Rehermann B, Nascimbeni M: Immunology of hepatitis B virus and hepatitis C virus infection. Nat Rev Immunol 2005, 5:215-29.

2. Lohse AW, Weiler-Normann C, Tiegs G: Immune-mediated liver injury. J Hepatol 2010, 52:136-44.

3. Webster GJ, Reignat $S$, Brown D, Ogg GS, Jones L, Seneviratne SL, Williams R, Dusheiko G, Bertoletti A: Longitudinal analysis of CD8+ T cells specific for structural and nonstructural hepatitis $B$ virus proteins in patients with chronic hepatitis B: implications for immunotherapy. J Virol 2004, 78:5707-19.
4. Roncador G, Brown PJ, Maestre L, Hue S, Martinez-Torrecuadrada JL, Ling KL, Pratap S, Toms C, Fox BC, Cerundolo V, Powrie F, Banham AH: Analysis of FOXP3 protein expression in human CD4+CD25+ regulatory T cells at the single-cell level. Eur J Immunol 2005, 35:1681-91.

5. Hirota K, Yoshitomi H, Tanaka S, Nomura T, Yamaguchi T, Iwakura Y, Sakaguchi N, Sakaguchi S: T cell self-reactivity forms a cytokine milieu for spontaneous development of IL-17+ Th cells that cause autoimmune arthritis. J Exp Med 2007, 204:41-7.

6. Leifeld L, Cheng S, Ramakers J, Dumoulin FL, Trautwein C, Sauerbruch T, Spengler U: Imbalanced intrahepatic expression of interleukin 12, interferon gamma, and interleukin 10 in fulminant hepatitis $B$. Hepatology 2002, 36:1001-8.

7. Stoop JN, Claassen MA, Woltman AM, Binda RS, Kuipers EJ, Janssen HL, van der Molen RG, Boonstra A: Intrahepatic regulatory T cells are phenotypically distinct from their peripheral counterparts in chronic HBV patients. Clin Immunol 2008, 129:419-27.

8. Stoop JN, van der Molen RG, Baan CC, van der Laan LJ, Kuipers EJ, Kusters JG, Janssen HL: Regulatory T cells contribute to the impaired immune response in patients with chronic hepatitis $B$ virus infection. Hepatology 2005, 41:771-8.

9. Xu D, Fu J, Jin L, Zhang H, Zhou C, Zou Z, Zhao JM, Zhang B, Shi M, Ding $X$, Tang $Z$, Fu YX, Wang FS: Circulating and liver resident CD4+CD25 + regulatory $T$ cells actively influence the antiviral immune response and disease progression in patients with hepatitis B. J Immunol 2006, 177:739-47.

10. Kleinschek MA, Owyang AM, Joyce-Shaikh B, Langrish $C L$, Chen $Y$, Gorman DM, Blumenschein WM, McClanahan T, Brombacher F, Hurst SD, Kastelein RA, Cua DJ: IL-25 regulates Th17 function in autoimmune inflammation. J Exp Med 2007, 204:161-70.

11. Sallusto F, Lanzavecchia A: Human Th17 cells in infection and autoimmunity. Microbes Infect 2009, 11:620-4.

12. Romagnani S, Maggi E, Liotta F, Cosmi L, Annunziato F: Properties and origin of human Th17 cells. Mol Immunol 2009, 47:3-7.

13. Ge J, Wang K, Meng QH, Qi ZX, Meng FL, Fan YC: Implication of Th17 and Th1 cells in patients with chronic active hepatitis B. J Clin Immunol 2010, 30:60-7.

14. Zhang JY, Zhang Z, Lin F, Zou ZS, Xu RN, Jin L, Fu JL, Shi F, Shi M, Wang HF, Wang FS: Interleukin-17-producing CD4(+) T cells increase with severity of liver damage in patients with chronic hepatitis B. Hepatology 2010, 51:81-91.

15. Zhang Z, Chen D, Yao J, Zhang H, Jin L, Shi M, Zhang H, Wang FS: Increased infiltration of intrahepatic DC subsets closely correlate with viral control and liver injury in immune active pediatric patients with chronic hepatitis B. Clin Immunol 2007, 122:173-80.

16. O'Connor RA, Taams LS, Anderton SM: Translational mini-review series on Th17 cells: CD4 T helper cells: functional plasticity and differential sensitivity to regulatory $T$ cell-mediated regulation. Clin Exp Immunol 2010, 159:137-47.

17. Miossec P: IL-17 and Th17 cells in human inflammatory diseases. Microbes Infect 2009, 11:625-30.

18. Duerr RH, Taylor KD, Brant SR, Rioux JD, Silverberg MS, Daly MJ, Steinhart AH, Abraham C, Regueiro M, Griffiths A, Dassopoulos T, Bitton A, Yang H, Targan S, Datta LW, Kistner EO, Schumm LP, Lee AT, Gregersen PK, Barmada MM, Rotter Jl, Nicolae DL, Cho JH: A genome-wide association study identifies IL23R as an inflammatory bowel disease gene. Science 2006, 314:1461-3.

19. Weaver CT, Hatton RD: Interplay between the TH17 and TReg cell lineages: a (co-)evolutionary perspective. Nat Rev Immunol 2009, 9:883-9.

20. Nistala $K$, Moncrieffe $H$, Newton KR, Varsani $H$, Hunter $P$, Wedderburn LR: Interleukin-17-producing $T$ cells are enriched in the joints of children with arthritis, but have a reciprocal relationship to regulatory $T$ cell numbers. Arthritis Rheum 2008, 58:875-87.

21. Manigold T, Racanelli V: T-cell regulation by CD4 regulatory $T$ cells during hepatitis B and C virus infections: facts and controversies. Lancet Infect Dis 2007, 7:804-13.

22. Gupta S: Immune homeostasis: regulatory T cells (Treg) and molecules. J Clin Immunol 2008, 28:617-8.

23. Pernis $A B$ : Th17 cells in rheumatoid arthritis and systemic lupus erythematosus. J Intern Med 2009, 265:644-52.

24. Di Cesare A, Di Meglio P, Nestle FO: The IL-23/Th17 axis in the immunopathogenesis of psoriasis. J Invest Dermatol 2009, 129:1339-50. 
25. Annunziato F, Cosmi L, Santarlasci V, Maggi L, Liotta F, Mazzinghi B, Parente E, Fili L, Ferri S, Frosali F, Giudici F, Romagnani P, Parronchi P, Tonelli F, Maggi E, Romagnani S: Phenotypic and functional features of human Th17 cells. J Exp Med 2007, 204:1849-61.

26. Lemmers A, Moreno C, Gustot T, Marechal R, Degre D, Demetter P, de Nadai P, Geerts A, Quertinmont E, Vercruysse V, Le Moine O, Devière J: The interleukin-17 pathway is involved in human alcoholic liver disease. Hepatology 2009, 49:646-57.

27. Kuang DM, Peng C, Zhao Q, Wu Y, Chen MS, Zheng L: Activated monocytes in peritumoral stroma of hepatocellular carcinoma promote expansion of memory T helper 17 cells. Hepatology 2010, 51:154-64.

28. Lee JH, Cho ML, Kim Jl, Moon YM, Oh HJ, Kim GT, Ryu S, Baek SH, Lee SH, Kim HY, Kim SI: Interleukin 17 (IL-17) increases the expression of Toll-like receptor-2, 4, and 9 by increasing IL-1 beta and IL- 6 production in autoimmune arthritis. J Rheumatol 2009, 36:684-92.

29. Martin-Orozco N, Muranski P, Chung Y, Yang XO, Yamazaki T, Lu S, Hwu P, Restifo NP, Overwijk WW, Dong C: T Helper 17 Cells Promote Cytotoxic T Cell Activation in Tumor Immunity. Immunity 2009, 31:787-98.

30. Li N, Bian H, Zhang J, Li X, Ji X, Zhang Y: The Th17/Treg imbalance exists in patients with heart failure with normal ejection fraction and heart failure with reduced ejection fraction. Clin Chim Acta 2010, 411:1963-8.

31. Li J, Wang L, Wang S, Zhu H, Ye P, Xie A, Shen B, Liu C, Guo C, Fu Q, Zhang K, Xia J: The Treg/Th17 imbalance in patients with idiopathic dilated cardiomyopathy. Scand J Immunol 2010, 71:298-303.

32. Korn T, Bettelli E, Oukka M, Kuchroo VK: IL-17 and Th17 Cells. Annu Rev Immuno 2009, 27:485-517.

33. Mucida D, Park Y, Kim G, Turovskaya O, Scott I, Kronenberg M, Cheroutre H: Reciprocal TH17 and regulatory T cell differentiation mediated by retinoic acid. Science 2007, 317:256-60.

34. Laurence A, Tato CM, Davidson TS, Kanno Y, Chen Z, Yao Z, Blank RB, Meylan F, Siegel R, Hennighausen L, Shevach EM, O'shea JJ: Interleukin-2 signaling via STAT5 constrains T helper 17 cell generation. Immunity 2007, 26:371-81

35. Kryczek I, Wei S, Zou L, Altuwaijir S, Szeliga W, Kolls J, Chang A, Zou W: Cutting edge: Th17 and regulatory $T$ cell dynamics and the regulation by IL-2 in the tumor microenvironment. J Immunol 2007, 178:6730-3.

36. Pyzik M, Piccirillo CA: TGF-beta1 modulates Foxp3 expression and regulatory activity in distinct CD4+ T cell subsets. J Leukoc Biol 2007, 82:335-46

37. Manel N, Unutmaz D, Littman DR: The differentiation of human $\mathrm{T}(\mathrm{H})-17$ cells requires transforming growth factor-beta and induction of the nuclear receptor RORgammat. Nat Immunol 2008, 9:641-9.

38. Voo KS, Wang YH, Santori FR, Boggiano C, Wang YH, Arima K, Bover L, Hanabuchi S, Khalili J, Marinova E, Zheng B, Littman DR, Liu YJ: Identification of IL-17-producing FOXP3+ regulatory T cells in humans. Proc Natl Acad Sci USA 2009, 106:4793-8.

39. Ayyoub M, Deknuydt F, Raimbaud I, Dousset C, Leveque L, Bioley G, Valmori D: Human memory FOXP3+ Tregs secrete IL-17 ex vivo and constitutively express the $\mathrm{T}(\mathrm{H}) 17$ lineage-specific transcription factor RORgamma t. Proc Natl Acad Sci USA 2009, 106:8635-40.

40. Zhang L, Yang XQ, Cheng J, Hui RS, Gao TW: Increased Th17 cells are accompanied by FoxP3(+) Treg cell accumulation and correlated with psoriasis disease severity. Clin Immunol 2010, 135:108-17.

doi:10.1186/1471-2172-12-25

Cite this article as: Wang et al:: Activated IL-23/IL-17 pathway closely correlates with increased Foxp3 expression in livers of chronic hepatitis B patients. BMC Immunology 2011 12:25.

\section{Submit your next manuscript to BioMed Central and take full advantage of:}

- Convenient online submission

- Thorough peer review

- No space constraints or color figure charges

- Immediate publication on acceptance

- Inclusion in PubMed, CAS, Scopus and Google Scholar

- Research which is freely available for redistribution

Submit your manuscript at www.biomedcentral.com/submit
Biomed Central 